\title{
Talking about the 'r' word: a right to a health system that is free of racism
}

Carmen Partera,g, Donna Murrayb ${ }^{\mathrm{b}}$, Janine Mohamed ${ }^{\mathrm{c}}$, Boe Rambaldinia Tom Calma ${ }^{a}$, Shawn Wilson ${ }^{d}$, Donna Hartz ${ }^{\mathrm{e}}$, Josephine Gwynn ${ }^{\mathrm{a}, \mathrm{f}}$ and John Skinnera

a Poche Centre for Indigenous Health, University of Sydney, NSW, Australia

b Indigenous Allied Health Australia, Canberra, ACT, Australia

c Lowitja Institute, Melbourne, VIC, Australia

a Gnibi College of Indigenous Australian Peoples, Southern Cross University, Lismore, NSW, Australia

e Molly Wardaguga Research Centre, College of Nursing \& Midwifery, Charles Darwin University, NT, Australia

${ }^{f}$ Faculty of Medicine and Health, University of Sydney, NSW, Australia

g Corresponding author: c.parter@uq.edu.au

\section{Article history}

Publication date: March 2021

Citation: Parter C, Murray D, Mohamed J, Rambaldini B, Calma T, Wilson S, Hartz D, Gwynn J, Skinner J. Talking about the 'r' word: a right to a health system that is free of racism. Public Health Res Pract. 2021;31(1):e3112102. https://doi. org/10.17061/phrp3112102

\section{Key points}

- Indigenous knowledges relating to cultural ways of being, knowing and doing must be front and centre to any public health response

- A deep-seated resistance to addressing institutional and systemic racism and racist attitudes prevent the implementation and sharing of Indigenous knowledges and Indigenous cultures

- Public health policy makers and practitioners must start identifying and talking about racism, to help actively address racism

\section{Abstract}

Australia's local, state, territory and federal governments have agreed that the 10-year life expectancy gap between Indigenous and non-Indigenous Australians will be closed by 2031. However, annual Closing the Gap reports tabled by the various prime ministers in the Australian Parliament (for the past 12 years) have consistently indicated that the life expectancy gap continues to widen. Australia has seen more than three decades of government policies since the landmark 1989 National Aboriginal health strategy. What has been missing from these policy commitments is the genuine enactment of the knowledges that are held by Indigenous Australians relating to their cultural ways of being, knowing and doing. Privileging Indigenous knowledges, cultures and voices must be front and centre in developing, designing and implementing policies and programs. The sharing of power, provision of resources, culturally informed reflective policy making, and program design are critical elements. In this paper, we provide a conceptual model of practice, working at the cultural interface where knowledges are valued and innovations can occur. This model of practice is where knowledges and cultures can co-exist, and it could be the answer to Closing the Gap in life expectancy by 2031. Despite a growing willingness and need to consider these models, there remains a deep-seated resistance to identifying and addressing institutional and systemic racism and racist attitudes, including unconscious biases held by individuals. Further, western non-Indigenous worldviews of ways of being, knowing and doing continue to dominate the decisions and actions of governments - and consequentially dominate public health policies and practices. There is an unacceptable standard approach, for and about Indigenous health instead of with Indigenous peoples, resulting in the neglectful dismissal of Indigenous knowledges and Indigenous cultures of ways of being, knowing and doing. 


\section{Key points cont.}

- Working at the cultural interface where knowledge systems and cultures can co-exist and thrive is imperative to Indigenous Australians reclaiming pathways to better health

- Critical reflective practice is warranted to understand racism and institutional racism on health outcomes

\section{Introduction}

The elevation and implementation of Indigenous knowledges relating to cultural ways of being, knowing and doing are the principal factors required to close the 10-year life expectancy gap between Indigenous and non-Indigenous peoples. Ways of being concern the ordering of reality and how lives are lived within that reality. Indigenous ways of being acknowledge that everything is connected, interrelated and nonhierarchial, involving the living and non-living and including the unknown. ${ }^{1}$ Ways of being are a reflection of ways of knowing and ways of doing. Ways of knowing are concerned with how knowledges are created and passed along to others. For Indigenous peoples, knowledge is communally shared and passed on orally through stories that trace the origins of their Nations and reflect Indigenous peoples' lived experiences gathered intergenerationally over thousands of years. ${ }^{1,2}$ Ways of doing includes the practices one engages in, or how things get done, that are directed by one's values and belief systems. Indigenous ways of doing is underpinned by mutual obligation and accountability, as demonstrated through respect, reciprocity and responsibility to their relations. ${ }^{1}$ Indigenous ways of being, knowing and doing comprise worldviews that stand in stark contrast to the non-Indigenous euro-Australian worldviews. The Indigenous system is collective and interconnected, whereas the non-Indigenous system is individualistic and separated into parts that are not connected. Worldviews are not simple to define or explain. Working at the cultural interface, where worldviews can either collide or respectfully exchange, emphasises the importance of Indigenous health workers, leaders, organisations and community. ${ }^{2}$

If real transformational change in the health status of Indigenous Australians is to be achieved, then the knowledges as well as the cultures of Indigenous peoples must be front and centre in all public health policy and programming responses. Unfortunately, the knowledges and cultures held by Indigenous Australians are not fully acknowledged or recognised and are often dismissed as irrelevant. ${ }^{3}$ For far too long, non-Indigenous and western scientific and biomedical knowledges of ways of being, knowing and doing have dominated and informed public health policies and programs. Consistent with the United Nations declaration on the rights of Indigenous peoples, the public health sector must provide the means for Indigenous Australians to self-determine and rightfully practise their knowledges and cultures of ways of being, knowing and doing. ${ }^{4}$ More than 30 years have passed since the 1989 National Aboriginal health strategy declared an Indigenous health crisis. ${ }^{5}$ Consistent government efforts to address this health crisis have been futile. ${ }^{6}$ Nonetheless, emphasising the centrality of culture for Indigenous Australians and acknowledging the reality of racism in a public policy instrument like the Australian Government's National Aboriginal and Torres Strait Islander health plan 2013-2023, has created an opportunity to position Indigenous peoples and their knowledges at the forefront of public health responses and policy. ${ }^{7}$ Unfortunately, despite a willingness among some senior bureaucrats, politicians and academics, ingrained racist paradigms continue to sustain the health disparities and inequities, and social, economic and political inequalities that Indigenous Australians continue to experience. ${ }^{8-10}$

\section{What do we know so far?}

The efforts and investments over these past three decades have only seen the slightest improvements to the 10-year life expectancy gap between Indigenous and non-Indigenous peoples. ${ }^{11}$ Further, the social determinants of health and the legacy of colonisation continues to contribute substantially to the social, economic and political inequalities experienced by Indigenous peoples. ${ }^{11}$

Although there have been many plans and strategies, along with hundreds of millions of dollars in state, territory, and federal funding since the 1989 National Aboriginal health strategy was introduced, there have been limited improvements in health outcomes. Also, Indigenous wellbeing in the mainstream health system continues to decline with avoidable negative conditions and deaths widening. ${ }^{11}$ 
Figure 1. Working at the cultural interface where knowledge exchange occurs leading to innovations through cultural infusion - adaptation of the policy cycle $^{3,17,18}$

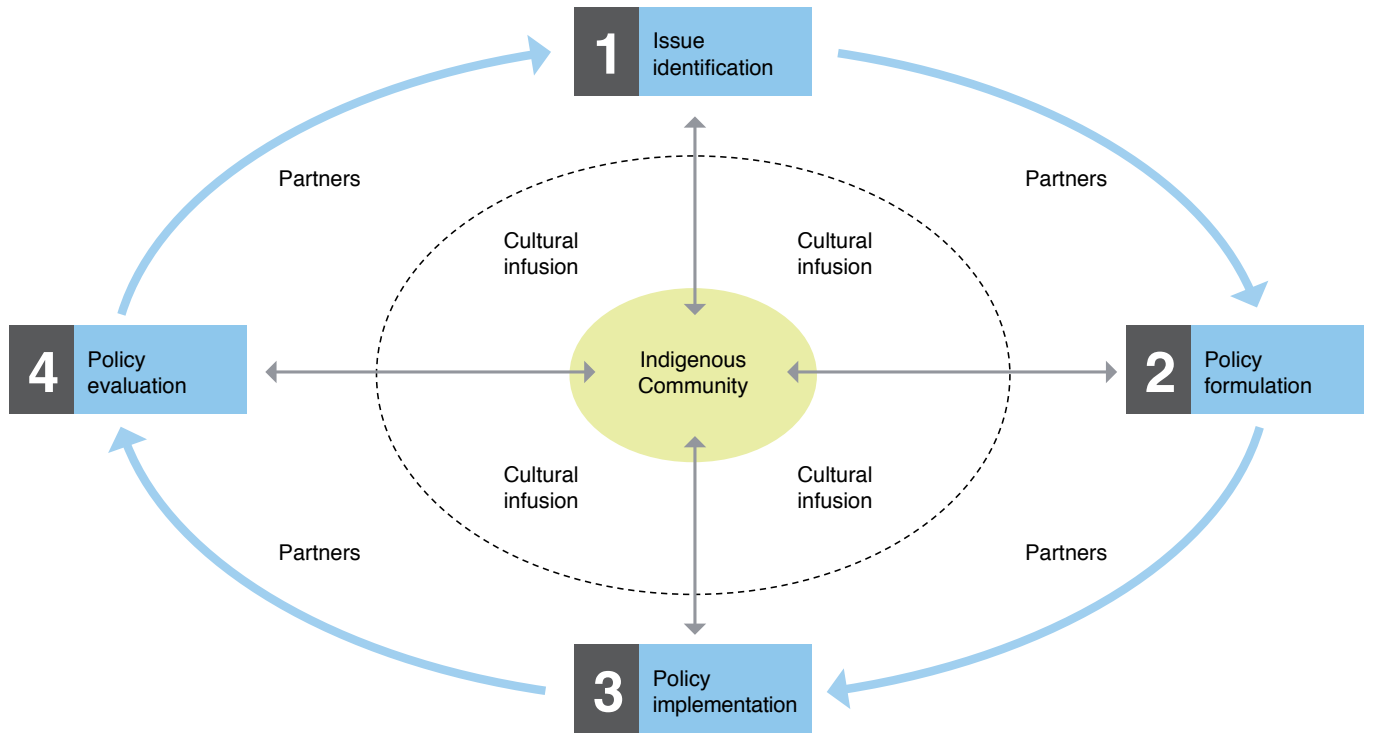

\section{What needs to happen?}

The new national Closing the Gap Agreement, made between the Coalition of Peaks and all levels of governments, have committed to a range of reforms including "systemic and structural transformation of mainstream government organisations". ${ }^{12}$ All governments have agreed to eliminate racism with inclusion of Indigenous cultures and truth-telling underpinning their policy responses. ${ }^{12}$ Additionally, a national summit called "for more transparency, truth-telling, power-sharing and culture-informed decision-making practices integrated within policy productions, program implementation and evaluation strategies". ${ }^{13}$

Reinventing institutions and transforming their structures, systems and practices requires an insurgency that challenges the dominance of non-Indigenous scientific western and biomedical knowledges, which have been responsible for determining policy and program decisions about the health of Indigenous Australians. ${ }^{14,15}$ That is not to say that there is no place for non-Indigenous western science. On the contrary, the knowledges and cultures held by Indigenous Australians must be recognised, valued and be front and centre to public policy and programming, and public health practice. Importantly, they can complement and co-exist with western knowledges. However, where knowledges meet at that cultural interface, Indigenous knowledges and cultures are subjugated. ${ }^{3,16}$ Innovations are inevitable if those knowledge systems and cultures are recognised as independent entities able to complement the other through cultural infusion. ${ }^{16,17}$

Therefore, Indigenous Australians must be provided with the means and opportunity to rightfully self-determine and govern their affairs. Mainstream governance structures within organisations must strive towards sharing power equally including privileging Indigenous voices, knowledges and cultural ways of being, knowing and doing in policy production and service design.

\section{Discussion}

Racism is more than an individual issue. When systemic injustices remain, unspoken or accepted, an unethical white privilege is fostered. When individuals and groups point out systemic injustices and inequities, the dominant culture is made accountable. ${ }^{19}$

Recognising the reality of racism and bringing Indigenous Australians' knowledge and cultures to the forefront of government decisions and actions continues. Communities remain strong with their aspirations and positive that governments have finally started to hear their calls. But is this enough? Transformation requires critical reflective practice ${ }^{21-24}$ from the public health sector and its practitioners. Based on government legacy it is obvious that government actions have not been enough. ${ }^{3}$ Connection to culture continues to be portrayed as an Indigenous Australian problem ${ }^{20}$, rather than Indigenous Australians reclaiming pathways to better health.

Australia has seen consecutive National Aboriginal and Torres Strait Islander health plans that have consistently spoken about the relevance of culture and the holistic nature of health. Yet the rights of Indigenous Australians, as espoused in the United Nations declaration on the rights of Indigenous peoples ${ }^{4}$, remain compromised - specifically, in relation to being able to self-determine rightfully and freely, without prejudice or biases, their cultural expressions and knowledges in how health and healthcare can be practised. ${ }^{4}$ Also, despite the emergence of Indigenous cultures in public policies and programs, there is no recognition of the knowledges held by Indigenous Australians and their 
intrinsic relationship to Indigenous cultures. ${ }^{3}$ This is racism and a result of racism in its many forms. Further, issues of institutional and systemic racism, racist attitudes, unconscious biases and non-Indigenous western worldviews of ways of being, knowing and doing continue to prevail and prevent effective policy and programming design and implementation. Finally, research that includes Indigenous science and methodological practice on the role of racist paradigms and their rules, norms and behaviours in shaping health systems, their organisations, and individuals' behaviour will provide greater critical reflective ${ }^{21-26}$ understanding of when, where and how to act so transformative change occurs.

\section{Conclusion}

Given the limited successes of governments' policy efforts to closing the life expectancy gap between Indigenous and non-Indigenous Australians, elevating and implementing Indigenous knowledges and cultures of ways of being, knowing and doing are principal factors for achieving meaningful critical reflective practice and transformational sustainable change. Further, this may assist to not merely close the gap in life expectancy, but foster an environment for all Indigenous Australians where their knowledges and cultures of ways of being, knowing and doing is central. To enable the knowledges and cultures held by Indigenous Australians requires the sharing of power and resources to support the privileging of Indigenous voice(s) in policy and public health program design. To do so, it is critical to work at the cultural interface where cultural infusion occurs to create those shared and inventive solutions that are necessary to address the health of Indigenous Australians. Furthermore, a strong commitment and understanding from governments, policy makers and public health practitioners about their role in enabling Indigenous knowledges and cultural ways of being, knowing and doing is imperative. As is identifying and talking about racism underpinned by critical reflective practice. Unleashing Indigenous peoples' knowledges and their cultures is the answer for achieving the transformative systemic and structural reforms agreed by governments.

\section{Acknowledgements}

The Poche Centre for Indigenous Health at the University of Sydney sponsors CP as an academic fellow under the Wingara Mura Leadership Academy program. The National Health Leadership Forum, which is the national representative health forum for national Aboriginal and Torres Strait Islander peak health bodies in Australia, provided in-kind support, guidance and advice for this manuscript.

\section{Peer review and provenance}

Externally peer reviewed, not commissioned.

\section{Competing interests}

None declared.

\section{Author contributions}

$\mathrm{CP}$ led the design and writing of the manuscript. Each co-author made important intellectual contributions and was involved in reviewing and editing the manuscript. All co-authors approved the final manuscript.

\section{References}

1. Parter $\mathrm{C}$, Wilson $\mathrm{S}$. My research is my story: a methodological framework of inquiry told through storytelling by a doctor of philosophy student. Qualitative Inquiry. 2021.

2. Parter C. Decolonising public health policies: rightfully giving effect to Aboriginal and Torres Strait Islander peoples' knowledges and cultures of ways of being, knowing and doing in public health policies. Sydney: University of Sydney; 2021 [cited 2021 Feb 28]. Available from: hdl.handle.net/2123/24415

3. Parter C, Wilson S, Hartz LD. The closing the gap (CTG) refresh: should Aboriginal and Torres Strait Islander culture be incorporated in the CTG framework? How? Aust N Z J Public Health. 2019;43(1):5-7.

4. United Nations Department of Economic and Social Affairs. United Nations declaration on the rights of Indigenous peoples. Geneva: UN; 2007 [cited 2017 Feb 6]. Available from: www.un.org/development/desa/ indigenouspeoples/wp-content/uploads/sites/19/2018/11/ UNDRIP_E_web.pdf

5. National Aboriginal Health Strategy Working Party. A national Aboriginal health strategy. Canberra: Government of Australia; 1989.

6. Holland C. A ten year review: the closing the gap strategy and recommendations for reset. Canberra: The Closing the Gap Campaign Steering Committee for Indigenous Health Equality, 2018 [cited 31 Aug 2018]. Available from: www.humanrights.gov.au/our-work/aboriginal-and-torresstrait-islander-social-justice/publications/close-gap-10year-review

7. Department of Health. National Aboriginal and Torres Strait Islander health plan 2013-2023. Canberra: Commonwealth of Australia; 2013 [cited 2021 Feb 15]. Available from: www1.health.gov.au/internet/main/ publishing.nsf/content/b92e980680486c3bca257bf0001b af01/\$file/health-plan.pdf

8. Arabena K. Future initiatives to improve the health and wellbeing of Aboriginal and Torres Strait Islander peoples. Med J Aust. 2013;199(1):22. 
9. Durey A, Thompson SC, Wood M. Time to bring down the twin towers in poor Aboriginal hospital care: addressing institutional racism and misunderstandings in communication. Intern Med J. 2012;42(1):17-22.

10. Markwick A, Ansari Z, Clinch D, McNeil J. Experiences of racism among Aboriginal and Torres Strait Islander adults living in the Australian state of Victoria: a cross-sectional population-based study. BMC Pub Health. 2019;19(1):1-14.

11. Australian Health Ministers' Advisory Council. Aboriginal and Torres Strait Islander health performance framework: 2017 report. Canberra: Commonwealth of Australia; 2017 [cited 2021 Feb 15]. Available from: www.indigenoushpf. gov.au/getattachment/362c60ea-9af9-459c-892708c9fb5582df/attachment.aspx

12. Australian Government. National agreement on closing the gap. Canberra: National Indigenous Australian Agency; 2020 [cited 2020 Jul 30]. Available from: www. closingthegap.gov.au/sites/default/files/files/nationalagreement-ctg.pdf

13. NSW Government. Communique of the 5th national Aboriginal and Torres Strait Islander health summit. Sydney: NSW Health; 2018 [cited 2018 Jul 30] Available from: www.health.nsw.gov.au/aboriginal/Documents/ national-summit-communique.pdf

14. Smith LT. Decolonizing methodologies: research and Indigenous peoples. Dunedin: University of Otago Press; 1999.

15. Walter M, Andersen C. Indigenous statistics: a quantitative research methodology. Walnut Creek, CA: Left Coast Press Incorporation; 2013.

16. Nakata M. Disciplining the savages: savaging the disciplines. Canberra: Aboriginal Studies Press; 2007.

17. Parter C. Cultural dimensions in policy development: a case study - the NSW Aboriginal justice plan. Public Administration Today. 2005;4:4-8.

18. Buse K, Mays N, Walt G. Making health policy. 2nd Ed. London: Open University Press; 2012.
19. O'Dowd MF. Explainer: what is systemic racism and institutional racism. The Conversation; 2020 February 5 [cited 2020 June 3] Available from: theconversation. com/explainer-what-is-systemic-racism-and-institutionalracism-131152

20. Pholi K, Black D, Richards C. Is 'Close the Gap' a useful approach to improving the health and wellbeing of Indigenous Australian? Australian Review of Public Affairs. 2009;9(2):1-13.

21. Rix L, Barclay L, Wilson S. Can a white nurse get it? 'Reflective practice' and the non-Indigenous clinician/ researcher working with Aboriginal people. Rural Remote Health. 2014;14(2):2679.

22. Rix L, Rotumah D. Chapter 10 - healing mainstream health: building understanding and respect for Indigenous knowledges. In: Frawley J, Russell G, Sherwood J, editors. Cultural competency and the higher education sector - Australian perspectives, policies and practices. Singapore: Springer; 2020. p. 175-95.

23. Broussine M, Ahmad Y. The development of public managers' reflexive capacities. Teaching Public Administration. 2013;31(18):18-28.

24. Cunliffe AL, Jun JS. The need for reflexivity in public administration. Administration and Society. 2005:37:225-42.

25. Fredericks B, Bargallie D. Chapter 16 - an Indigenous Australian cultural competence course: talking culture, race and power. In: Frawley J, Russell G, Sherwood J, editors. Cultural competency and the higher education sector - Australian perspectives, policies and practices. Singapore: Springer; 2020. p. 295-304.

26. Sherwood J, Mohamad J. Chapter 9 - Racism a social determinant of Indigenous health: yarning about cultural safety and cultural competence strategies to improve Indigenous health. In: Frawley J, Russell G, Sherwood J, editors. Cultural competency and the higher education sector - Australian perspectives, policies and practices. Singapore: Springer; 2020. p. 159-74.

\section{Copyright: (C) $(1)(0)$}

(C) 2021 Parter et al. This article is licensed under the Creative Commons Attribution-NonCommercial-ShareAlike 4.0 International Licence, which allows others to redistribute, adapt and share this work non-commercially provided they attribute the work and any adapted version of it is distributed under the same Creative Commons licence terms. See: www.creativecommons.org/licenses/by-nc-sa/4.0/ 